\title{
Diversity of Microcystis aeruginosa in the Klamath River and San Francisco Bay delta, California, USA
}

\author{
Pia H. Moisander ${ }^{1, *}$, Peggy W. Lehman ${ }^{2}$, Mari Ochiai ${ }^{1}$, Susan Corum ${ }^{3}$ \\ ${ }^{1}$ University of California Santa Cruz, Ocean Sciences Department, 1156 High Street, Santa Cruz, California 95064, USA \\ ${ }^{2}$ California Department of Water Resources, 901 P Street, Sacramento, California 95814, USA \\ ${ }^{3}$ Karuk Tribe of California, Department of Natural Resources, PO Box 282, Orleans, California 95556. USA
}

\begin{abstract}
Blooms of the toxin-producing cyanobacterium Microcystis aeruginosa have recently appeared in the Klamath River (KR) and San Francisco Bay delta (SFBD), California, USA. We investigated Microcystis diversity in these systems by targeting cpcBA (phycocyanin gene intergenic spacer and flanking regions) and mcyA gene (encodes part of a peptide synthetase cluster for production of the toxin microcystin). Distinct differences in Microcystis populations in the KR reservoirs (Copco and Iron Gate reservoirs) and SFBD were found in both gene loci, and diversity in the mcyA gene discriminated the populations in the 2 ecosystems entirely. The $c p c B A$ sequences from KR fell into 2 main clusters, and were closely similar to sequences from North and South America, Europe, Asia, and Africa. The majority of the $c p c B A$ sequences in populations from SFBD formed a unique group, while the remaining sequences were closely similar to those from KR. Salinity, soluble reactive phosphorus concentration, $\mathrm{pH}$, water transparency, and $\mathrm{NH}_{4}{ }^{+}$and $\mathrm{NO}_{3}{ }^{-}+\mathrm{NO}_{2}{ }^{-}$concentrations were significantly different in the 2 systems. The consistent differences in the 2 genetic markers between KR and SFBD populations suggest that Microcystis populations in the 2 watersheds have had limited connectivity or a different initial source population, or that environmental selection is creating distinct Microcystis populations in the eutrophic KR freshwater reservoirs and the saltwater influenced SFBD. Although Microcystis is globally distributed in temporal and subtropical climates, this study suggests local microdiversity exists and may be linked with environmental regulation.
\end{abstract}

KEY WORDS: Microcystis - Phycocyanin intergenic spacer - Microcystin synthetase ${ }^{c} p c B A \cdot$ mсуA $\cdot$ Estuaries $\cdot$ Reservoirs $\cdot$ Ecotype

\section{INTRODUCTION}

Several freshwater Cyanobacteria, including some strains of species within the genera Microcystis, Anabaena, Planktothrix and Nostoc produce microcystins, cyclic heptapeptides that are inhibitors of eukaryotic protein phosphatases (Sivonen \& Jones 1999). Microcystis aeruginosa is a particularly common bloom-forming cyanobacterium in many eutrophic freshwaters (Bittencourt-Oliveira et al. 2001, Gobler et al. 2007) and some estuaries (Sellner et al. 1988, Robson \& Hamilton 2003), where microcystins may cause serious adverse health effects for humans, domestic animals and wildlife (Chorus \& Bartram 1999). Microcystins are assembled by a nonribosomal peptide syn- thetase enzyme complex encoded by the mcy gene cluster (Meissner et al. 1996), and > 70 microcystin congeners with variable toxicity have been identified (Chorus \& Bartram 1999). Ability to produce different microcystin variants may be regulated both by environmental factors and genotype (Kaebernick et al. 2000, Downing et al. 2005, Kardinaal et al. 2007), but these links are not well understood.

Several studies have investigated Microcystis diversity and studies with 16S rRNA have suggested at least some Microcystis populations (genotypes) are cosmopolitan (Neilan et al. 1997, Lepère et al. 2000). However, Microcystis spp. diversity based on 16S rRNA gene or phycocyanin intergenic spacer $(c p c B A)$ is not 
congruent with morphology, species identification (Neilan et al. 1995, Bittencourt-Oliveira et al. 2001) or toxicity (Lyra et al. 2001, Tillett et al. 2001). Several diversity studies have focused on cultured Microcystis strains, while few studies exist on diversity in field populations, including studies in the North American Great Lakes (Rinta-Kanto \& Wilhelm 2006, Hotto et al. 2007) and Lake Taihu, China (Ye et al. 2009).

Little is known about environmental regulation of Microcystis diversity. Environmental conditions may select for different Microcystis strains that vary in toxicity and other physiological characteristics (Yoshida et al. 2007). Survival in laboratory conditions is variable (Wilson et al. 2005) and therefore some strains may be underrepresented in culture. Studies focusing on diversity of uncultured strains therefore expand our knowledge of the Microcystis diversity and allow investigation of links between environmental regulation and adaptation of Microcystis to specific environmental conditions, which may lead to 'ecotypes.'

Toxin producing Microcystis was only recently identified as a major bloom-forming taxon in Copco and Iron Gate reservoirs of the Klamath River (KR) (Jacoby \& Kann 2007) and San Francisco Bay delta (SFBD) estuary (Lehman et al. 2005) in northern California. Blooms in KR were first identified in 2005, and since then Microcystis abundance during the bloom season has frequently exceeded $10^{5}$ cells $\mathrm{ml}^{-1}$ (Jacoby \& Kann 2007), a level considered to have a moderate probability for adverse health effects to humans in recreational waters (WHO 2003). The blooms typically start in June or July in KR reservoirs where flow is restricted and an anoxic hypolimnion prevails during the phytoplankton growth season. The co-occurence of the nitrogen $\left(\mathrm{N}_{2}\right)$-fixing cyanobacterium Aphanizomenon sp. with Microcystis is common in these reservoirs (Kann \& Asarian 2007). Microcystis blooms were also recently reported from the SFBD, with widespread blooms first appearing in 1999 (Lehman et al. 2005, 2008). Here cell density exceeded $10^{6}$ cells $\mathrm{ml}^{-1}$ in 2007 (P. Lehman unpubl. data). Microcystin concentration in the surface layer was below the World Health Organization (WHO) drinking water advisory level of $1 \mathrm{\mu g} \mathrm{l}^{-1}$, which is considered a safe level for lifelong consumption (WHO 2003). However, the effect of Microcystis on the aquatic ecosystem is a concern because microcystin was present in the tissues of aquatic organisms at multiple trophic levels, including zooplankton and clams (Lehman et al. 2005, 2008). Although the presence of Microcystis in the brackish waters of SFBD could be due to flushing from freshwater reaches upstream, several culture studies have shown growth proceeded at maximum rates at salinities of up to $10 \mathrm{mg} \mathrm{l}^{-1} \mathrm{NaCl}$ (Robson \& Hamilton 2003, Verspagen et al. 2006, Tonk et al.
2007). Whether the salinity tolerance varies among Microcystis strains is unknown.

To our knowledge studies on genetic diversity of $\mathrm{Mi}$ crocystis from brackish water environments, or watersheds in the US Pacific Northwest have not been published. Comparison of Microcystis spp. diversity in KR and the geographically close, yet environmentally different SFBD, and other Microcystis populations worldwide will provide useful information on potential routes of Cyanobacteria introductions and whether the KR and SFBD ecosystems might select for specific Microcystis ecotypes. We used an intergenic spacer and flanking regions of 2 phycocyanin pigment genes $(c p c B A)$ and a peptide (microcystin) synthetase gene $m c y A$ in the diversity investigations. Use of $c p c B A$ allowed us to obtain information on diversity of both the toxic and non-toxic Microcystis strains, while the mcyA gene provided information on diversity of the toxic subpopulation of Microcystis. These target sequences allowed ecosystem comparisons because they have been used in several previous studies and public databases contain sequences from diverse systems worldwide. Further, measurement of environmental variables at the time of Microcystis sampling allowed comparison of environmental conditions between the 2 ecosystems and estimation of their effects on diversity.

\section{MATERIALS AND METHODS}

Study sites. KR is an important salmon habitat in the Pacific Northwest and has a watershed of $40795 \mathrm{~km}^{2}$ in southern Oregon and northern California, USA. The river starts at the outlet of the hypereutrophic Upper Klamath Lake and continues as a series of reservoirs and dams until it finally enters the Copco and Iron Gate reservoirs (Fig. 1). Below Iron Gate dam the river flows free for $300 \mathrm{~km}$ before entering the Pacific Ocean. Over the past decades the KR watershed above Iron Gate dam has experienced a multitude of human-induced modifications and pressures, including diversions and drainage for agriculture and generation of hydroelectric power (Eilers et al. 2004). The main sampling sites CR01 and IR01 are located in the main stem of the old river channel with depths of approximately 24 and $>30 \mathrm{~m}$, respectively (Fig. 1). An anoxic hypolimnion prevails in the reservoirs through the phytoplankton growth season. Nutrient budgets and phytoplankton trends in Copco and Iron Gate reservoirs have been described in detail by Kann \& Asarian (2007).

SFBD estuary is located approximately $480 \mathrm{~km}$ south of the KR reservoirs. It consists of an inland delta that flows into a chain of downstream marine bays, and creates one of the largest estuaries on the west coast of 


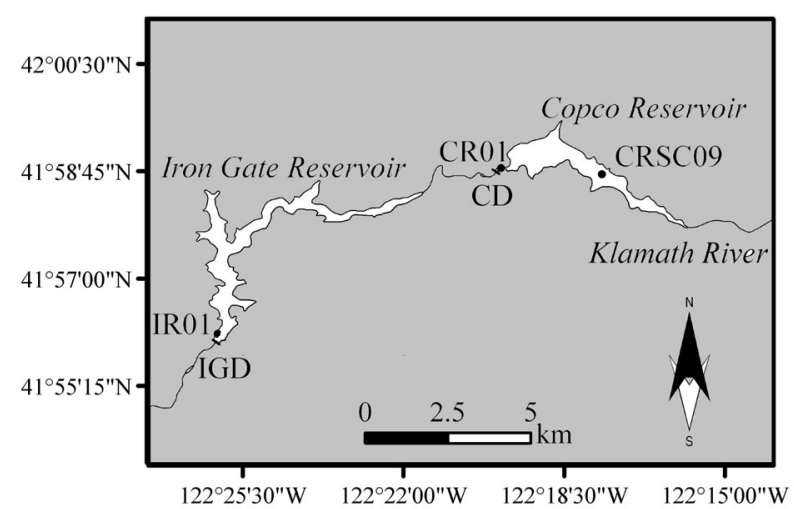

Fig. 1. Sampling sites CR01, IR01 and CRSC09 in the Klamath River reservoirs. CD: Copco Dam; IGD: Iron Gate dam

North America. The inland delta formed by the Sacramento River on the north and the San Joaquin River on the south contains $200 \mathrm{~km}^{2}$ of waterways. Together these rivers drain approximately $47 \%$ of the runoff in California. Depth varies in the delta from a few meters in the flooded islands in the center of the delta to $13 \mathrm{~m}$ in the main river channels. Tides are semidiurnal in the delta and reach $2 \mathrm{~m}$ in height with tidal velocities up to $30 \mathrm{~cm} \mathrm{~s}^{-1}$ and tidal excursions of $10 \mathrm{~km}$.

Sample collection and physico-chemical measurements. For KR reservoirs, water samples for diversity studies were collected at CR01 and IR01 between 14 June and 21 September 2007 (Fig. 1, Table 1). Additional water samples were collected on 7 August at CRSC09 (Fig. 1) and from a bioassay experiment enrichment study, conducted for CR01 on 26 June 2007 (Moisander et al. 2009). Water samples were collected from approximately $30 \mathrm{~cm}$ depth into sterile $50 \mathrm{ml}$ centrifuge tubes or 11 polycarbonate bottles. The samples were collected either during field experiments (Moisander et al. 2009), filtered and frozen in the field or shipped overnight on 'blue ice' (artificial ice packs) to University of California Santa Cruz (UCSC), where they were filtered upon arrival. From 1 to $50 \mathrm{ml}$ of the water sample was filtered onto a $0.2 \mu \mathrm{m}$ Supor membrane filter (Pall Gelman), placed in a $2 \mathrm{ml}$ bead beater tube (Biospec) with $0.2 \mathrm{~g}$ glass beads and flash frozen at $-80^{\circ} \mathrm{C}$. The samples were stored at $-20^{\circ} \mathrm{C}$ until extraction. At each station, temperature, $\mathrm{pH}$ and dissolved oxygen (DO) were determined using a multiparameter probe (Quanta), and water transparency was measured by Secchi disk. Water samples were also collected for measurement of dissolved inorganic nitrogen $\left(\mathrm{NH}_{4}{ }^{+}-\mathrm{N}, \mathrm{NO}_{3}{ }^{-}+\mathrm{NO}_{2}{ }^{-}-\mathrm{N}\left[\mathrm{NO}_{\mathrm{x}}\right]\right.$, soluble reactive phosphorus [SRP]), chlorophyll a (chl a) concentration and shipped overnight on blue ice to Aquatic Research, Seattle, Washington, for analysis. Methods were as follows: Environmental Protection Agency (EPA) 350.1 for $\mathrm{NH}_{4}{ }^{+}$, EPA 353.2 for $\mathrm{NO}_{\mathrm{x}}$, EPA 365.1 for

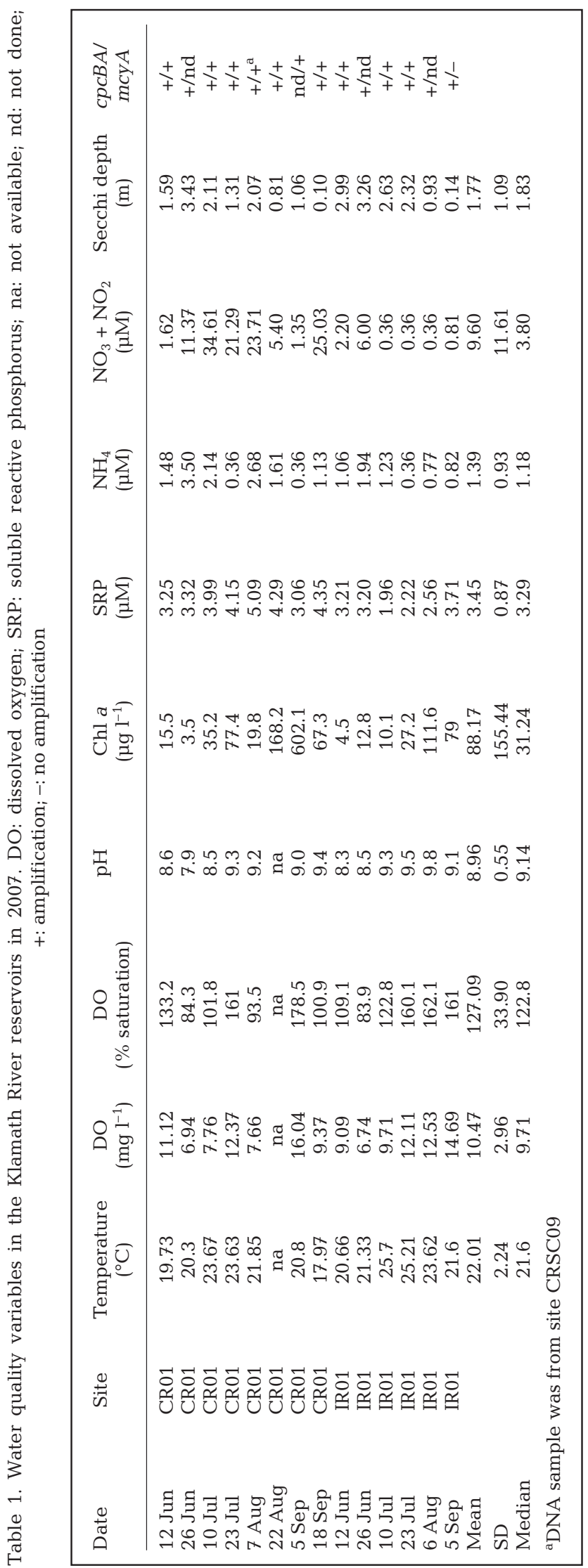


SRP (USEPA 1983) and $10200 \mathrm{H}$ for chl a (Clesceri et al. 1998).

The SFBD water samples were collected at 11 sites in August and September 2007 (Fig. 2, Table 2). Stations selected for the study represented different habitat types or beneficial use by recreational swimming (Stn BI), shallow water habitat (MI and FT), deep water channel (CV, VC, SM), native fish habitat (SJ, CI), drinking water supply (OR), deep water brackish (AT) and shallow water brackish (MG) habitat. Samples for DNA analyses were collected by a surface water grab into 21 acid washed bottles and stored on ice until filtration. Within $2 \mathrm{~h}$ of sampling, 10 to $50 \mathrm{ml}$ of sample water were filtered onto $0.2 \mu \mathrm{m}$ filters (Supor). Filters were placed in sterile bead beater tubes, immediately frozen on dry ice in the field and stored at $-80^{\circ} \mathrm{C}$. The tubes were shipped overnight on dry ice to UCSC and stored at $-20^{\circ} \mathrm{C}$. At each station in SFBD, surface water temperature, specific conductance and $\mathrm{pH}$ were measured (Yellow Springs Instruments 6600 sonde) and water transparency was measured by Secchi disk depth. Nutrient and chl a samples were analyzed at the California Department of Water Resources following identical methods as those used for KR. Salinity was calculated from specific conductance converted to chloride based on regression equations for each station and then converted to salinity by the equation, salinity $=$ chloride $\left(\mathrm{g} \mathrm{l}^{-1}\right) \times 1.80655$ (Clesceri et al. 1998).

Differences in environmental variables between the 2 watersheds were examined by independent sample $t$-tests (SPSS statistics software v. 17). Principal compo-

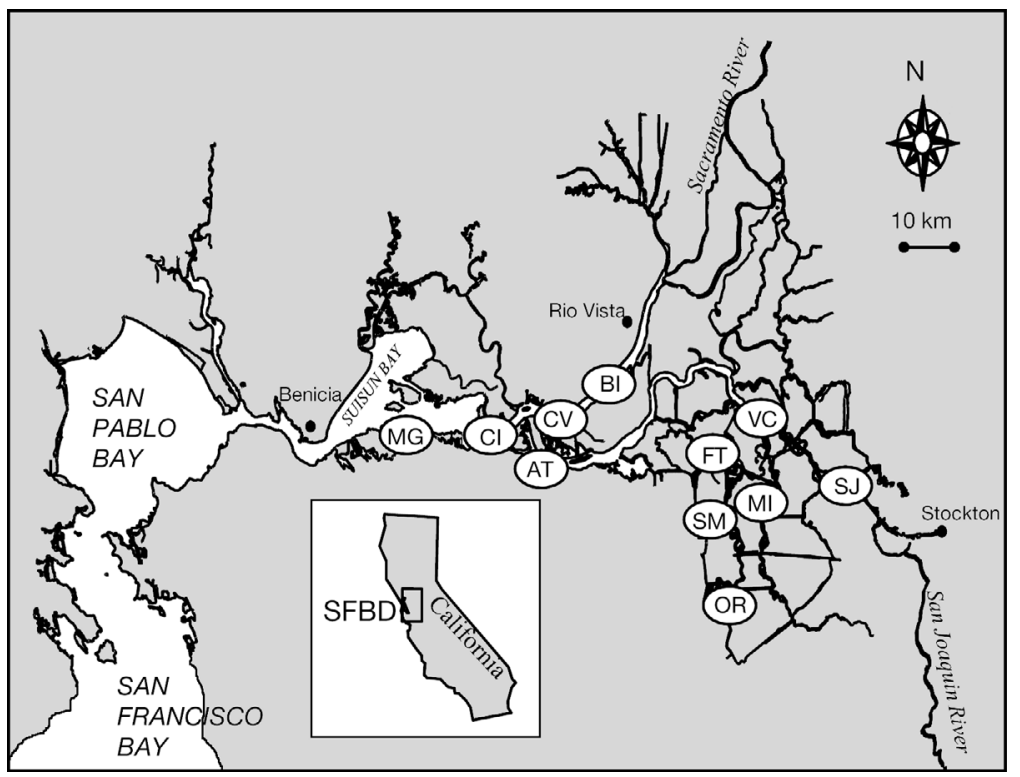

Fig. 2. Sampling sites in the San Francisco Bay delta (SFBD). BI: Brannon Island; CI: Chips Island; FT: Franks Tract; MI: Mildred Island; OR: Old River; MG: Middle Ground; AT: Antioch; SJ: San Joaquin River; SM: Sand Mound Slough; CV: Collinsville; VC: Venice Cut nent analysis was carried out with the variables that were significantly different between KR and SFBD. If necessary, values were log transformed before analysis to meet the test assumptions.

Two Microcystis sp. reference strains (strains StL.C3 and 2127, isolation sources unknown) obtained from A. Chapman (Greenwater Labs, Palatka, Florida) were used as positive controls. One Microcystis strain (Microcystis sp. KLA2) was isolated from the Copco reservoir on BG-11 media using repeated plating (Rippka 1988) and was included in the phylogenetic analysis. Microcystin production of the 3 strains was tested at the US Environmental Protection Agency (Richmond, California) using the enzyme-linked immunosorbent assay (ELISA) kit (Envirologix).

Nucleic acid analyses. DNA was extracted using a modified Plant Mini Kit (Qiagen) protocol (Moisander et al. 2008) with a final elution volume of $100 \mu \mathrm{l}$ in $\mathrm{AE}$ buffer (from the kit), and extracts were stored at $-20^{\circ} \mathrm{C}$. PCR was used to amplify an approximately $650 \mathrm{bp}$ cpcBA fragment. Each PCR reaction (50 $\mu \mathrm{l}$ total) contained $1 \times$ PCR buffer, $2.5 \mathrm{mmol} \mathrm{l}^{-1} \mathrm{MgCl}$ buffer, $3 \mu \mathrm{mol}$ $\mathrm{l}^{-1}$ of $c p c B A$ forward (5'-GGC TGC TTG TTT ACG CGA CA-3') and reverse (5'-CCA GTA CCA CCA GCA ACT AA-3') primers (Neilan et al. 1995), $200 \mathrm{mmol} \mathrm{l}^{-1}$ deoxynucleoside triphosphates (dNTP), $1 \mathrm{U}$ Platinum Taq (Invitrogen), and $2 \mu \mathrm{DNA}$ template. Amplification conditions included $95^{\circ} \mathrm{C}$ for $4 \mathrm{~min}$, followed by 30 cycles of $94^{\circ} \mathrm{C}$ for $1 \mathrm{~min}, 56^{\circ} \mathrm{C}$ for $30 \mathrm{~s}$, and $72^{\circ} \mathrm{C}$ for $1 \mathrm{~min}$, and finally $72^{\circ} \mathrm{C}$ for $7 \mathrm{~min}$. PCR was also used to amplify an approximately $250 \mathrm{bp}$ fragment of the mcyA gene. Each PCR reaction (50 $\mu$ l) comprised $1 \times$ PCR buffer, $2 \mathrm{mmol}$ $\mathrm{l}^{-1} \mathrm{MgCl}$ buffer, $1 \mu \mathrm{mol} \mathrm{l^{-1 }}$ of forward (5'AAA ATT AAA AGC CGT ATC AAA-3') and reverse (5'-AAA AGT GTT TTA TTA GCG GCT CAT-3') primers (Sigma Genosys) (Hisbergues et al. 2003),

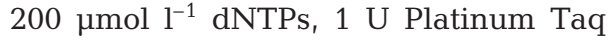
(Invitrogen) and $2 \mu \mathrm{l}$ of DNA template. Amplification conditions included $95^{\circ} \mathrm{C}$ for $5 \mathrm{~min}$, then 30 cycles of $94^{\circ} \mathrm{C}$ for $30 \mathrm{~s}$, $57^{\circ} \mathrm{C}$ for $30 \mathrm{~s}$, and $72^{\circ} \mathrm{C}$ for $30 \mathrm{~s}$, followed by $72^{\circ} \mathrm{C}$ for $7 \mathrm{~min}$.

All PCR products were electrophoresed on a $1.2 \%$ tris-acetic acidEDTA (TAE) gel, stained with SYBR Gold (Invitrogen) (1:10000) and visualized using a Bio-Rad gel documentation system. Bands were excised and purified using the Qiagen gel extraction kit and cloned into pGEM-T vectors (Promega). Plasmids were purified from overnight cultures using the Montage 96-well kit (Millipore). Sequencing was done at the 


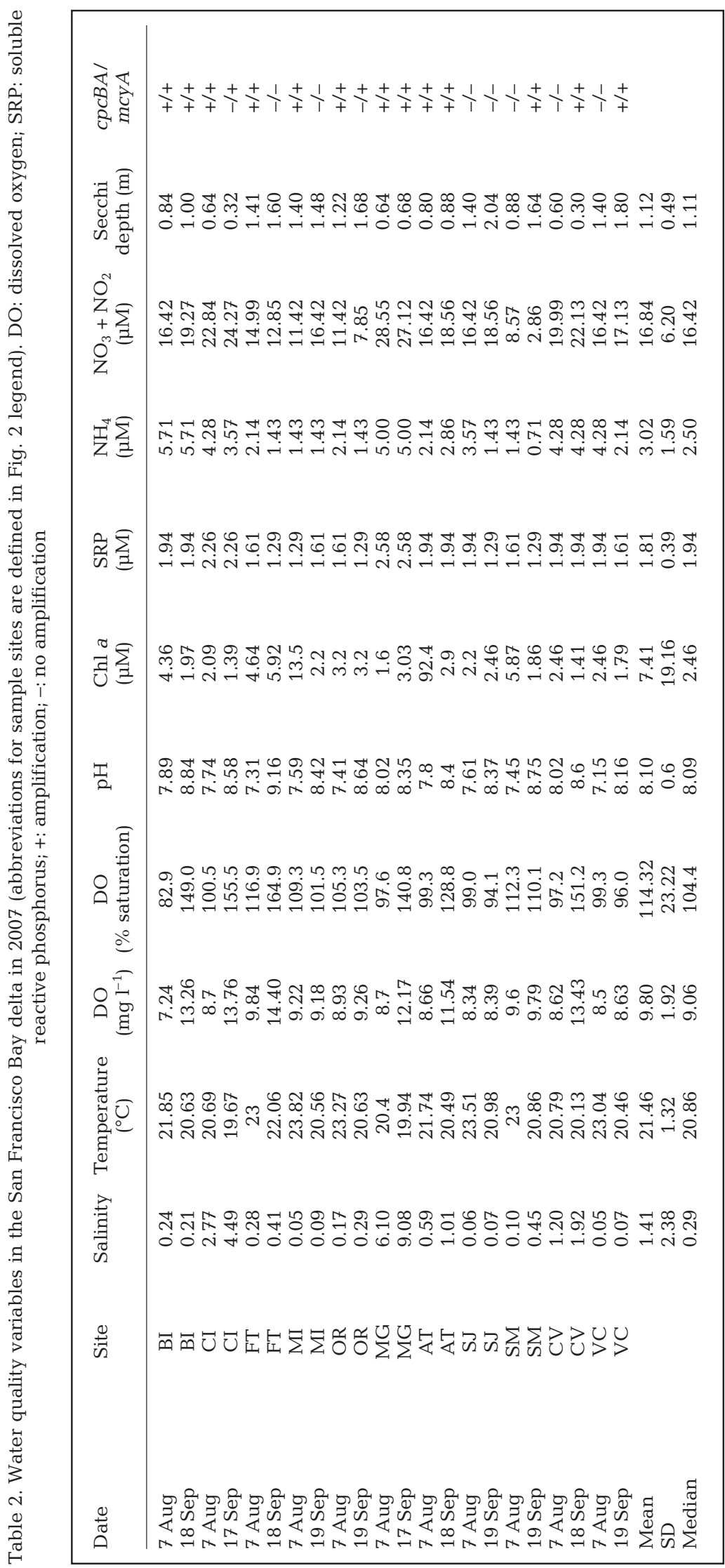

University of California Berkeley, sequencing facility. Sequences were trimmed using GCG software (Accelrys). Reference sequences were downloaded from GenBank to build $с p c B A$ and mсyA databases in Arb (Ludwig et al. 2004). The mcyA sequences (246 or $252 \mathrm{bp}$ fragments) were translated into amino acid (82 or 84 amino acid residues) and aligned in ClustalX, then imported into the database. The $\operatorname{coc} B A$ nucleotide sequences were aligned using ClustalW web interphase in European Molecular Biology Laboratory (EMBL), then imported to Arb. Additional sequences were aligned to the Clustal alignment using the integrated aligner feature in Arb. To include several $с p c B A$ reference sequences from GenBank with different length, the $c p c B A$ phylogenetic tree was built using an approximately 525 base nucleotide region. Phylogenetic trees were built using the neighborjoining method with Kimura correction for the mcy $A$ amino acid sequences and JukesCantor correction for $с p c B A$ nucleotide sequences in Arb. Bootstrapping was carried out with 500 replicates using MEGA v. 4 (Tamura et al. 2007).

Unique sequences at the DNA level from each sample were submitted to GenBank. The number of identical clones recovered is shown in Figs. $3 \& 4$. Sequences from this study are under GenBank accession numbers FJ469404-FJ469556.

\section{RESULTS}

\section{Environmental conditions}

Environmental data for KR and SFBD are shown in Tables $1 \& 2$, respectively. SRP, $\mathrm{NH}_{4}{ }^{+}, \mathrm{NO}_{\mathrm{x}}, \mathrm{chl} a$ and water transparency (Secchi depth) were significantly different between the 2 watersheds $(\mathrm{p}<0.05, \mathrm{n}=$ $35-36$, independent $t$-tests). SRP, $\mathrm{pH}$, chl a and Secchi depth were greater in the KR than in SFBD, while $\mathrm{NO}_{\mathrm{x}}$ and $\mathrm{NH}_{4}{ }^{+}$concentrations were greater in SFBD than in KR. There was no significant difference between the 2 watersheds in temperature or DO (concentration $\left[\mathrm{mg} \mathrm{l}^{-1}\right]$ or percent saturation). Environmental variables that were significantly different between $\mathrm{KR}$ and SFBD $\left(\mathrm{NO}_{\mathrm{x}}\right.$, $\mathrm{NH}_{4}{ }^{+}$, Secchi depth, $\mathrm{pH}$ and SRP) were included in a principal component analysis 


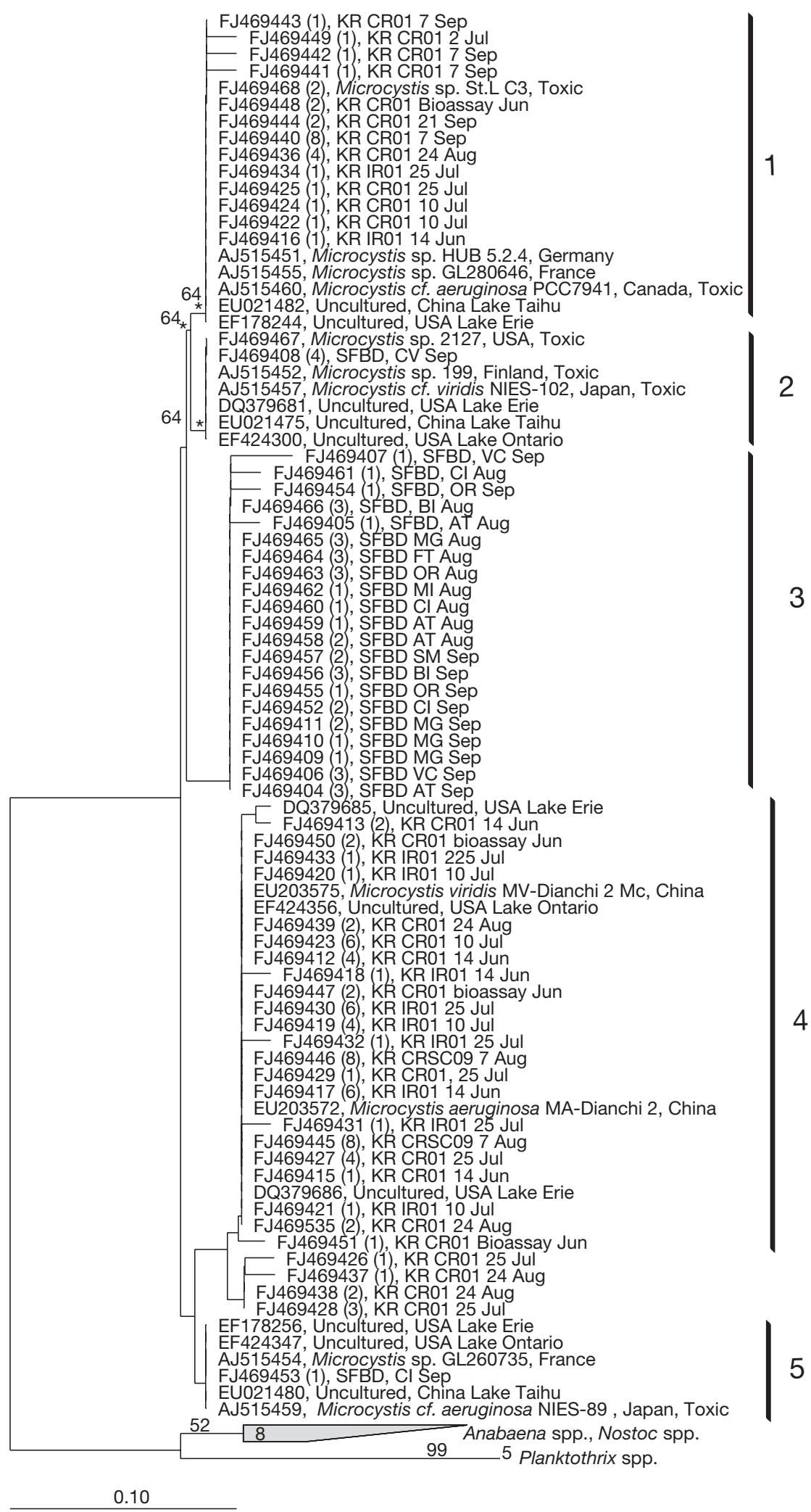

Fig. 3. Neighbor-joining tree of $m c y A$ based on alignment of 84 amino acids. Bootstrap values $>50$ are shown for 500 replicates. Number of identical clones from each sample is shown in parentheses. Toxicity of strains from the present study and reference strains (Lyra et al. 2001) is indicated. CR01 and KR01 are sample sites in the Klamath River reservoirs (KR); abbreviations for San Francisco Bay delta (SFBD) sample sites are defined in Fig. 2 legend. Scale indicates branch length of 0.1 substitutions per site 


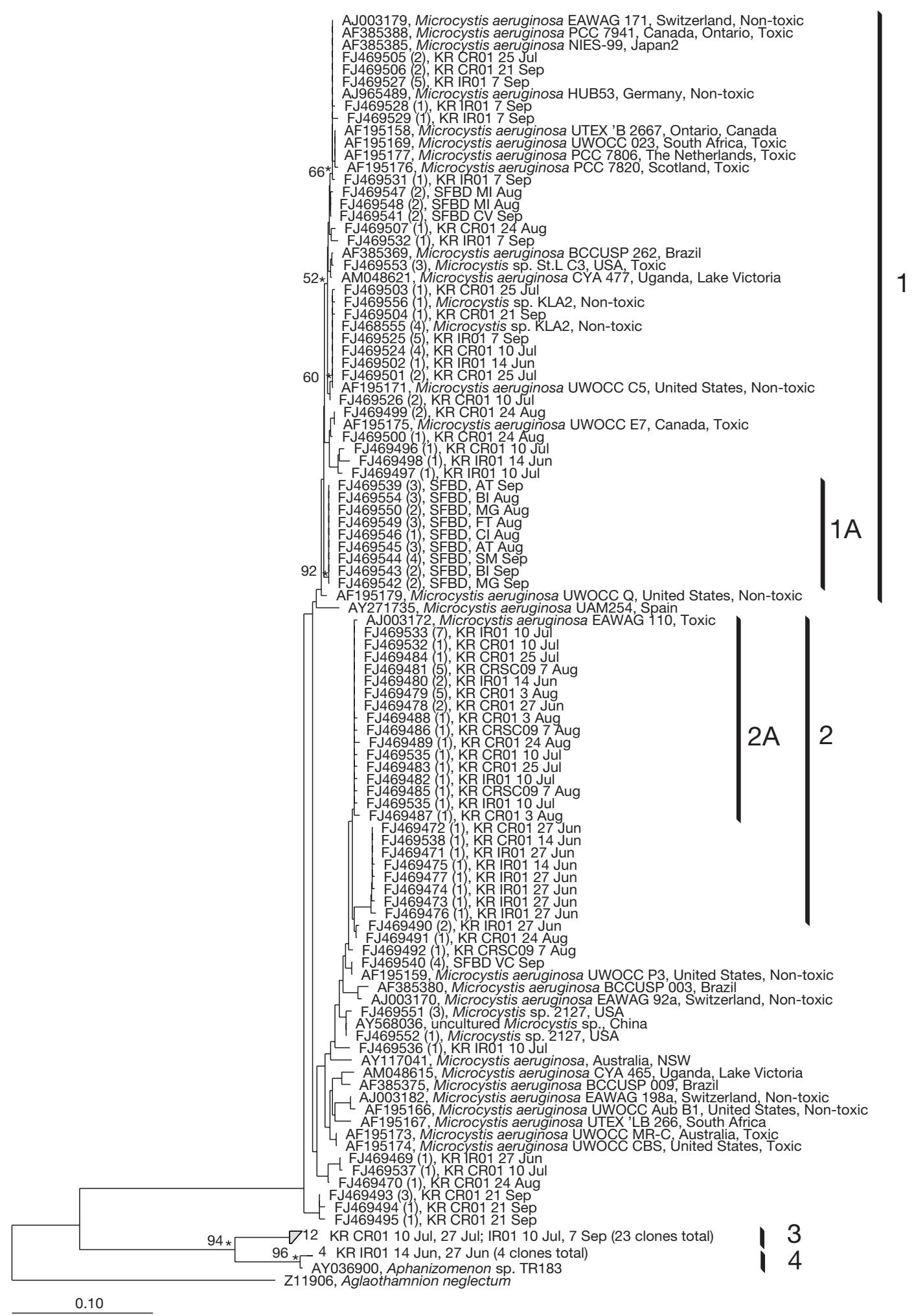

Fig. 4. Neighbor-joining tree of $c p c B A$ based on alignment of 575 nucleotides. Bootstrap values $>50$ are shown for 500 replicates. Number of identical clones from each sample is shown in parentheses. Toxicity of strains from the present study and reference strains (Lyra et al. 2001, Tillett et al. 2001) is indicated. CR01 and KR01 are sample sites in the Klamath River reservoirs (KR); abbreviations for San Francisco Bay delta (SFBD) sample sites are defined in Fig. 2 legend. Scale indicates branch length of 0.1 substitutions per site 
(PCA). PCA reduced the variability to 2 factors that described $69 \%$ of the data variance (Fig. 5). Component 1 had a positive correlation with $\mathrm{NO}_{\mathrm{x}}$ and $\mathrm{NO}_{4}{ }^{+}$, and a negative correlation with the Secchi depth, and described $42 \%$ of the data variance. Component 2 had a positive correlation with $\mathrm{pH}$ and SRP and described $26 \%$ of the data variance. Component 1 loadings were on average more negative in KR than in SFBD, suggesting dissolved inorganic nitrogen (DIN) concentrations were greater and water transparency was lower in SFBD than KR. KR samples had more positive loadings on Component 1 for Copco reservoir than for Iron Gate reservoir. In SFBD, samples taken from the Sacramento River and downstream from the confluence of the riverine and saline waters (CI, MG, CV and BI) had positive loadings on Component 1, while samples from the interior delta had negative loadings. Component 2 loadings were similar among stations in each watershed but differed between KR and SFBD. Component 2 had positive loadings for KR and negative loadings for SFBD, indicating that soluble $\mathrm{P}$ and $\mathrm{pH}$ were higher in KR.

\section{Diversity}

A total of 124 mcyA microcystin synthetase genes and 148 срсBA phycocyanin intergenic spacer sequences were recovered. All environmental mcyA sequences from both $\mathrm{KR}$ and SFBD clustered with Microcystis (Fig. 3). KR and SFBD mcyA sequences each fell into more than one cluster but were distinct. Several clusters did not have high bootstrap support due to closely related sequences. All SFBD sequences and some KR sequences had a 2-amino acid deletion

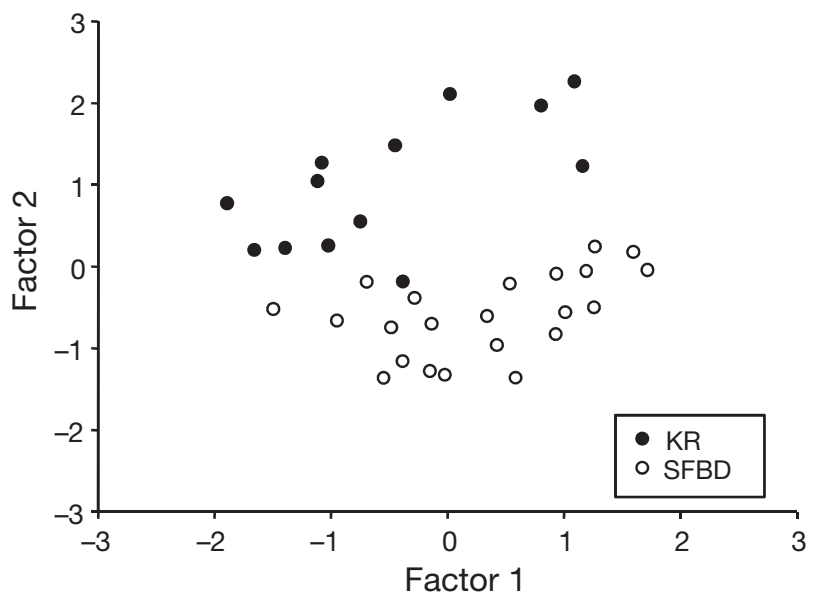

Fig. 5. Correlation of principal component scores from each sampling occasion with 2 principal components. Component 1 had a positive correlation with $\mathrm{NO}_{\mathrm{x}}$ and $\mathrm{NH}_{4}{ }^{+}$and a negative correlation with Secchi depth, and Component 2 had a positive correlation with $\mathrm{pH}$ and SRP (phenylalanine and alanine or tryptophan and alanine) in positions 79 and 80. In addition, SFBD sequences, with the exception of 4 identical sequences recovered from station CV in September (FJ469408), had threonine in position 49, while KR sequences had proline, leucine or serine in this position.

KR mcyA sequences fell into 2 main clusters (Clusters 1 and 4, Fig. 3) that had a high identity with sequences previously recovered from Lakes Erie and Ontario in the US (Rinta-Kanto \& Wilhelm 2006, Hotto et al. 2007) and Lake Taihu, China (Ye et al. 2009). KR sequences in mcyA Cluster 1 were also closely identical with sequences from lakes in Germany, France and Canada $(98.7 \%$ or greater nucleotide identity within all sequences in Cluster 1) (Hisbergues et al. 2003). Sequences in KR Cluster 4 had $97.9 \%$ or greater nucleotide identity. A few additional sequences from KR did not clearly fall to either cluster. Each KR sequence type was represented at most sampling occasions, but there were some exceptions. Cluster 1 type mcyA sequence was not found in KR at either IR01 or CR01 on June 12, or on August 7 at IR01, while Cluster 4 type mcyA sequence was not found at CR01 on September 21.

The mcyA gene amplified from 15 of the total of 22 samples from SFBD. The majority of sequences (total of 47 ) in these samples formed a unique cluster with a $96 \%$ or greater identity at the amino acid level and did not match any sequences in GenBank (Cluster 3). Of these gene sequences 39 also had 100\% amino acid identity $(99.1 \%$ or greater nucleotide identity). Sequences with low identity to the main SFBD sequence cluster were recovered from CV (September), VC (August), CI (August) and AT (September). Additionally, 2 SFBD sequences (from CV and CI in September) were different from the main cluster and the KR sequences. One of the SFBD mcyA sequence types was recovered at CI in September and had an identity of $99.1 \%$ or higher at the nucleotide level with sequences previously recovered from Lakes Ontario and Erie and lakes in China, Japan and France (Cluster 5). A second SFBD sequence type recovered from CV in September (Cluster 2) had a 99.6\% identity with sequences and strains isolated from lakes in Finland, Japan and China (Lake Taihu) and Lakes Erie and Ontario.

Sequences of $c p c B A$ from $\mathrm{KR}$ originated from either Microcystis (623 bp) or Aphanizomenon (634 or $660 \mathrm{bp}$ ) while all $с p c B A$ sequences from SFBD originated from Microcystis (Fig. 4). All срсBA identities discussed refer to identities at the nucleotide level. The сpсBA sequences from $\mathrm{KR}$ and SFBD fell into 2 main clusters, one of which (Cluster 1,97.1\% or greater identity among sequences) had approximately half of the unique KR sequences and all other SFBD sequences except those from VC in September (Fig. 4). 
With the exception of sequences from MI in August and CV and VC in September, SFBD sequences were $100 \%$ identical, with no exact matches found in GenBank (Cluster 1A). Cluster 1 had both toxic and nontoxic reference sequences that originated from Canada, the USA, Brazil, Japan, Uganda, South Africa and several countries in Europe. Sequences from the Microcystis sp. culture isolate KLA2 also fell into Cluster 1. However, despite repeated attempts, we were not able to amplify mcy $A$ from the isolate, and the microcystin test was negative, suggesting the strain is non-toxic.

Cluster 2 sequences in the $с p c B A$ phylogenetic tree had a $97.5 \%$ or greater identity. Cluster $2 \mathrm{~A}$ sequences had $99.2 \%$ or higher identity and included a sequence from a toxic Microcystis sp. (AJ003172) and a large group of KR sequences. The $c p c B A$ Cluster 2 had a 93.5 to $95.4 \%$ identity with Cluster 1 . The rest of the Microcystis reference strains and KR sequences fell in between the 2 clusters. There was some variability in KR sample evenness. The $с p c B A$ Cluster 2 sequence type was found at KR on every test occasion, while the Cluster 1 sequence type was not found at CR01 on June 12 and 26 and August 7, nor at IR01 on June 26.

The $с p c B A$ sequences from KR formed 2 groups for Aphanizomenon (Fig. 4). A sequence type obtained from samples taken at IR01 in June 14 and 27 (Cluster 4) had $98.9 \%$ or higher identity to A. flos-aquae TR183 isolated from the Baltic Sea (AY036900). The remaining sequences (Cluster 3) were 89.9 to $90.7 \%$ different from this cluster and had 96.9 to $97.4 \%$ identity with an Aphanizomenon sp. isolate from an Indiana lake (Barker et al. 2000). The Indiana lake sequence was not included in the phylogenetic analysis because at 351 nucleotides it was significantly shorter than the other sequences.

\section{DISCUSSION}

Toxic and non-toxic strains are not discriminated by diversity in the $с p c B A$ or the 16S rRNA gene (Lyra et al. 2001, Tillett et al. 2001). This was confirmed in the present study as toxic and non-toxic strains clustered randomly. For this reason, the toxicity of source organisms for individual $c p c B A$ sequences from $\mathrm{KR}$ and SFBD cannot be predicted based on their clustering in the phylogenetic tree. The toxic strains PCC7941, PCC7806 and PCC7820 from GenBank all fell in the срсBA Cluster 1, but were discriminated in a previous study using a long 16S rRNA fragment (Neilan et al. 1997). The toxic Microcystis reference strains NIES102 and NIES-89 separated into Clusters 1 and 5 in our $m c y A$ analysis and were also discriminated by the $16 \mathrm{~S}$ rRNA gene (Neilan et al. 1997, Lyra et al. 2001).
Several differences were observed between the KR and SFBD Microcystis populations for both mcyA and $c p c B A$ sequences, and dominant and unique sequence types were present in both populations. One reason for the unique genetic fingerprints in the 2 systems could be that different subpopulations of Microcystis were originally introduced to KR and SFBD, or alternatively, that different ecotypes are dominant in the 2 systems due to differences in environmental conditions. Our cloning and sequencing probably revealed only the most abundant sequence types from both systems and more extensive sampling and sequencing that included rare genotypes might reveal more overlap between the 2 populations. Nevertheless, the data strongly suggest distinct and persistent genetic populations dominate blooms in the $\mathrm{KR}$ reservoirs and SFBD. Our sampling had a high spatiotemporal coverage; therefore, the dominant Microcystis genotypes are likely to be represented in our clone libraries.

Although different habitat types were sampled from SFBD, the diversity was strikingly similar over 2 sampling occasions at each site, with only a few exceptions. Only 5 of the $41 \mathrm{mcy} A$ sequences isolated from the SFBD were not separate from sequences in KR and other ecosystems. These exceptions occurred at sites $\mathrm{CV}$ and CI near the confluence of the San Joaquin and Sacramento rivers. Here, freshwater from the rivers converge and meet the more brackish water seaward. However, since the presence of the divergent gene types was sporadic and the cloning effort was too small to reveal rare genotypes, it would be too speculative to suggest habitat type played a role in gene diversity.

In $\mathrm{KR}$, Microcystis $с p c B A$ and mcyA diversity was split between 2 main sequence types for each gene target. For $c p c B A$, one of the sequence types was closely similar, yet distinct from strains in SFBD. Cluster 1 срсBA and mcyA sequences were absent in KR early in the season; therefore, these data may reflect the influence of seasonal changes in environmental conditions on Microcystis diversity.

The fact that KR and SFBD had different Microcystis populations, and that neither mсуA nor срсBA sequences from SFBD had exact matches in the GenBank, could reflect the influence of environmental factors that potentially select for different Microcystis populations. In SFBD, Microcystis was detected in the entire range of salinities of 0.1 to 9.1. Although the diversity of Microcystis in brackish systems is not known, several studies have reported blooms of Microcystis in estuarine systems (e.g. Sellner et al. 1988, Verspagen et al. 2006). Reported salinity tolerance for growth in cultures has varied from 9.8-10 (Orr et al. 2004, Tonk et al. 2007) to 14-15 (Robson \& Hamilton 2003, Verspagen et al. 2006), suggesting strain-specific variability exists in salinity tolerance. The Microcystis 
mсуA and $c p c B A$ genotypes that were recovered from SFBD only and did not have matches in GenBank are potentially ones adapted to elevated salinities and may represent a brackish water ecotype.

On average, pH was slightly elevated in KR compared with SFBD and could have affected cyanobacterial growth; however, the relationship of cyanobacterial blooms and $\mathrm{pH}$ is complex. Cyanobacteria as a group may have a competitive advantage under low dissolved inorganic carbon (DIC) conditions (high $\mathrm{pH}$ ) due to their carbon concentration mechanism (Shapiro 1989) and an increase in $\mathrm{pH}$ and decrease in DIC is commonly observed as Microcystis biomass increases in cultures and field populations (Shapiro 1989, Qiu \& Gao 2002). Microcystis growth is, however, enhanced by elevated DIC and low pH in the growth media (Qiu \& Gao 2002), so a high $\mathrm{pH}$ is not a requirement for growth. In a previous study, highest growth rates were detected at $\mathrm{pH} 8.5$, with growth still proceeding at $\mathrm{pH}$ 9.5 at reduced rates (Chu et al. 2007), while active photosynthesis continues even at pH 10 (Shapiro 1989). In another study, growth rates were equal at a $\mathrm{pH}$ range of 7 to 10 (McLachlan \& Gorham 1962). Further, Microcystis has been isolated from soils with a $\mathrm{pH}$ as low as 4.9 to 6.2 (Gopalaswamy et al. 2007). These results probably reflect multiple genotypes that may have different growth characteristics; however, they indicate that as a taxon Microcystis has a broad tolerance for $\mathrm{pH}$. Bearing this in mind, $\mathrm{pH}$ in both KR and SFBD was probably in the optimal range for Microcystis growth. Theoretically, a higher $\mathrm{pH}$ in KR would select for strains that have more effective carbon acquisition mechanisms; however, the difference in mean $\mathrm{pH}$ among the systems was small, so it is unlikely $\mathrm{pH}$ played a major role in selection of genotypes.

Average water transparency was lower in SFBD than in KR. SFBD is a turbid system where water transparency is controlled by high suspended sediment concentration and light limits primary productivity (Cole \& Cloern 1984). Non-toxic Microcystis strains can potentially outcompete toxic strains under low light conditions in both field populations and cultures (Kardinaal et al. 2007). The presence of a unique $m c y A$ genotype in SFBD and coincident measurements of microcystin (P. Lehman unpubl. data) suggest these low light levels did not inhibit the growth of toxic strains in the population. Instead, toxic and non-toxic genotypes may be adapted to low light levels in SFBD.

Dissolved inorganic phosphorus, measured as SRP, was consistently elevated in KR compared with SFBD, so strains with a higher affinity to P in SFBD would theoretically have a growth benefit. Little is known about the effect of $P$ availability on the competitive strength of different Microcystis strains. Availability of P affects buoyancy regulation, such that under nutrient-limiting conditions the cells tend to sink, which will reduce light levels the cells experience. Therefore, lower P in SFBD should further reduce the light levels the cells experience in SFBD.

The mean DIN concentration was greater in SFBD than in $\mathrm{KR}$, but it was variable among samples in both systems. High concentrations of $\mathrm{NO}_{3}{ }^{-}$may promote increased relative abundance of toxic Microcystis strains in field populations (Yoshida et al. 2007) and would potentially favor toxic Microcystis in SFBD, which would oppose the enhancement of non-toxic Microcystis strains in low light. In addition, the relatively high $\mathrm{NH}_{4}{ }^{+}$concentration in SFBD may be favorable for all or some Microcystis strains (Takamura et al. 1987).

The results from the present study suggest investigations of effects of salinity, light, $\mathrm{P}, \mathrm{NO}_{\mathrm{x}}$ and $\mathrm{NH}_{4}{ }^{+}$on competitive strength of different Microcystis strains and genotypes would be informative. Additional environmental factors that were not detected in the present study may have equal or greater importance in explaining diversity in KR and SFBD.

Amplification of the microcystin synthetase gene mcyA from Microcystis and no other microcystin producers confirms it is the major source of microcystins in both systems. However, the mсyA gene and fragment did not amplify from some samples. Possible reasons for this are that the targets were not present or PCR inhibition occurred. We did not carry out additional PCR optimization for samples that did not amplify, so it is possible some samples with no amplification did, in fact, have some targets present. However, no PCR inhibition was detected in quantitative PCR carried out on parallel samples (data not shown) suggesting the extract purification was effective and likelihood of significant inhibition in regular PCR is low. Also, although absence of mcy genes almost certainly is an indication of lack of genetic machinery for microcystin production (Neilan et al. 1999), mcy genes have been detected in some strains that did not produce microcystin in laboratory conditions (Tillett et al. 2001).

Some of the $c p c B A$ sequences for the phycocyanin intergenic spacer from both KR and SFBD were closely similar to sequences reported worldwide, suggesting cosmopolitan distribution of at least some of the Microcystis cpcBA genotypes. Previous studies with $16 \mathrm{~S}$ rRNA sequences also indicated several genotypes of Microcystis had cosmopolitan distribution (Neilan et al. 1995, Lepère et al. 2000). However, high within-system diversity can occur with $с p c B A$ or mcyA (Bittencourt-Oliveira et al. 2001, Rinta-Kanto \& Wilhelm 2006). Considerable genotype richness was detected in both $c p c B A$ and mcyA among KR and SFBD populations. A large proportion of sequences did not match any sequences from cultured strains available in Gen- 
Bank. These findings could indicate either multiple introduction events, high richness in the original introduced population or a long time had passed since the original introduction. Microcystis may have been present in KR and SFBD for much longer than the recent bloom events that have reached public awareness. Microcystis is known to be present in many lakes and reservoirs in Oregon and California; however, little is known about historic trends in these systems (Jacoby \& Kann 2007).

Several sequences identical to Aphanizomenon sp. were recovered from the KR samples. Interestingly, 2 types of $c p c B A$ fragments were recovered, both of which grouped with Aphanizomenon sp. Typically, срсBA fragment length is conserved at the genus level; however, Aphanizomenon appears to be an exception (Baker et al. 2000). The 2 Aphanizomenon sp. sequence groups were farther apart than is typically considered representative for a single species. Based on this difference, the Baltic Sea Aphanizomenon sp. was proposed to be distinct from A. flos-aquae (Barker et al. 2000). The presence of the 2 Aphanizomenon sp. genotypes in the KR reservoirs suggests the Baltic Sea genotype is not restricted to brackish water environments. Neither Baltic Sea nor Klamath Aphanizomenon blooms are known to be toxic (Sivonen et al. 1989, Carmichael et al. 2000).

Recent studies suggest environmental selection plays an important role in shaping microbial diversity (Martiny et al. 2006), based on the early idea that 'everything is everywhere, but environment selects' (Baas Becking 1934). For example, microbial community composition changes along estuarine salinity gradients (Crump et al. 2004). Methodological approaches are central in determining what conclusions can be drawn from biogeography studies. A multi-locus approach is important in any biogeography study since genes that are considered conserved (such as the 16S rRNA gene) often do not reveal all functional diversity at the strain level that may be of ecological importance, such as the ability to produce toxins in Microcystis. Microcystin genes appear to have coevolved with housekeeping genes and therefore the effect of horizontal gene transfer has been low (Rantala et al. 2004); however, they have repeatedly been lost in different cyanobacterial lineages. The mcyA sequence diversity in those strains in which the genes are still present is therefore likely to reflect cyanobacterial evolutionary history, not just random recombination events. Future studies focusing on multiple microcystin and other gene loci will provide a clearer picture of Microcystis diversity linked with evolutionary history and environmental controls in these and other environments.

In the present study we showed that dominant Microcystis genotypes in the KR and SFBD were dis- tinct. The large spatiotemporal sample coverage provides evidence that the data reflect dominant and persistent populations and are therefore ecologically relevant. The observed differences may be due to environmental regulation or geographic isolation, or both. Environmental differences identified between the 2 ecosystems suggest environmental regulation may well have an effect on differential selection of genotypes in KR and SFBD. As light and other conditions that vary with depth play an important role in regulating Microcystis blooms, further variability may emerge when populations are investigated at different depths in the water column. Further investigations of Microcystis diversity will also be informative in starting to link environmental and genotype regulation to types of microcystins produced by this common bloomforming cyanobacterium.

Acknowledgements. M. M. Puckett and S. J. Steinberg (Humbold State University, Institute for Spatial Analysis) are acknowledged for the map of the Klamath reservoirs, as is A. Lincoff (USEPA, Richmond, California) for the microcystin analysis, A. Chapman (Greenwater Labs, Florida) for providing the Microcystis cultures, J. Kann (Aquatic Ecosystem Sciences, LLC) for KR physicochemical data, Bryte laboratory (California Department of Water Resources) for SFBD nutrient data, and J. Zehr (University of California Santa Cruz) for use of instrumentation and other facilities. Pacificorp and L. Prendergast are acknowledged for assistance in the field. Comments from 3 anonymous reviewers significantly improved the manuscript. This study was supported by a Klamath Watershed Institute grant to P.H.M. and California Bay Delta Authority (CALFED) grant S-05-SC-056 to P.W.L.

\section{LITERATURE CITED}

Baas Becking LGM (1934) Geobiologie of inleiding tot de milieukunde. WP Van Stockum \& Zoon, The Hague

Barker GLA, Konopka A, Handley BA, Hayes PK (2000) Genetic variation in Aphanizomenon (Cyanobacteria) colonies from the Baltic Sea and North America. J Phycol 36:947-950

Bittencourt-Oliveira MC, Oliveira MC, Bolch CJS (2001) Genetic variability of Brazilian strains of the Microcystis aeruginosa complex (Cyanobacteria/Cyanophycea) using the phycocyanin intergenic spacer and flanking regions (срсBA). J Phycol 37:810-818

Carmichael WW, Drapeau C, Anderson DM (2000) Harvesting Aphanizomenon flos-aquae Ralfs ex Born. \& Flah. var. flos-aquae (Cyanobacteria) from Klamath Lake for human dietary use. J Appl Phycol 12:585-595

Chorus I, Bartram J (1999) Toxic cyanobacteria in water. A guide to their public health consequences, monitoring and management. World Health Organization. E \& FN Spon, London

Chu ZS, Jin XC, Iwami N, Inamori YH (2007) The effect of temperature on growth characteristics and competitions of Microcystis aeruginosa and Oscillatoria mougeotii in a shallow, eutrophic lake simulator system. Hydrobiologia 581:217-223

Clesceri LS, Greenberg AE, Eaton DE, Franson MAH (1998) 
Standard methods for the examination of water and wastewater, 20th edn. American Public Health Association, Washington, DC

> Cole B, Cloern J (1984) Significance of biomass and light availability to phytoplankton productivity in San Francisco Bay. Mar Ecol Prog Ser 17:15-24

> Crump BC, Hopkinson CS, Sogin ML, Hobbie JE (2004) Microbial biogeography along an estuarine salinity gradient: combined influences of bacterial growth and residence time. Appl Environ Microbiol 70:1494-1505

Downing TG, Meyer C, Gehringer MM, van de Venter M (2005) Microcystin content of Microcystis aeruginosa is modulated by nitrogen uptake rate relative to specific growth rate or carbon fixation rate. Environ Toxicol 20:257-262

Eilers JM, Kann J, Cornett J, Moser K, St. Amand A (2004) Paleolimnological evidence of change in a shallow, hypereutrophic lake: Upper Klamath Lake, Oregon, USA. Hydrobiologia 520:7-18

Gobler CJ, Davis TW, Coyne KJ, Boyer GL (2007) Interactive influences of nutrient loading, zooplankton grazing, and microcystin synthetase expression on cyanobacterial bloom dynamics in a eutrophic New York lake. Harmful Algae 6:119-133

Gopalaswamy G, Karthikeyan CV, Raghu R, Udayasuriyan V, Apte SK (2007) Identification of acid-stress-tolerant proteins from promising cyanobacterial isolates. J Appl Phycol 19:631-639

Hisbergues M, Christiansen G, Rouhiainen L, Sivonen K, Borner T (2003) PCR-based identification of microcystinproducing genotypes of different cyanobacterial genera. Arch Microbiol 180:402-410

> Hotto AM, Satchwell MF, Boyer GL (2007) Molecular characterization of potential microcystin-producing cyanobacteria in Lake Ontario embayments and nearshore waters. Appl Environ Microbiol 73:4570-4578

Jacoby JM, Kann J (2007) The occurrence and response to toxic cyanobacteria in the Pacific Northwest, North America. Lake Reservoir Manag 23:123-143

Kaebernick M, Neilan BA, Borner T, Dittman E (2000) Light and transcriptional response of the Microcystis biosynthesis gene cluster. Appl Environ Microbiol 66:3387-3392

Kann J, Asarian E (2007) Nutrient budgets and phytoplankton trends in Iron Gate and Copco Reservoirs, California, May 2005-May 2006. Final Technical Report to the State Water Resources Control Board, Sacramento, CA

> Kardinaal WEA, Tonk L, Janse I, Hol S, Slot P, Huisman J, Visser PM (2007) Competition for light between toxic and non-toxic strains of the harmful cyanobacterium Microcystis. Appl Environ Microbiol 73:2939-2946

Lehman PW, Boyer G, Hall C, Waller S, Gehrts K (2005) Distribution and toxicity of a new colonial Microcystis aeruginosa bloom in the San Francisco Bay Estuary, California. Hydrobiologia 541:87-99

Lehman PW, Boyer G, Satchwell M, Waller S (2008) The influence of environmental conditions on the seasonal variation of Microcystis cell density and microcystins concentration in San Francisco Estuary. Hydrobiologia 600: 187-204

Lepère C, Wilmotte A, Meyer B (2000) Molecular diversity of Microcystis strains (Cyanophyceae, Chroococcales) based on 16S rDNA sequences. Syst Geogr Plants 70:275-283

Ludwig W, Strunk O, Westram R, Richter L, Meier H, and 27 others (2004) ARB: a software environment for sequence data. Nucleic Acids Res 32:1363-1371

Lyra C, Suomalainen S, Gugger M, Vezie C, Sundman P, Paulin L, Sivonen K (2001) Molecular characterization of planktic cyanobacteria of Anabaena, Aphanizomenon,
Microcystis and Planktothrix genera. Int J Syst Evol Microbiol 51:513-526

McLachlan J, Gorham PR (1962) Effects of pH and nitrogen sources on growth of Microcystis aeruginosa Kutz. Can J Microbiol 8:1-11

- Martiny JBH, Bohannan BJM, Brown JH, Colwell RK and others (2006) Microbial biogeography: putting microorganisms on the map. Nat Rev Microbiol 4:102-112

> Meissner K, Dittman E, Borner T (1996) Toxic and non-toxic strains of the cyanobacterium Microcystis aeruginosa contain sequences homologous to peptide synthetase genes. FEMS Microbiol Lett 135:295-303

> Moisander PH, Beinart BA, Voss M, Zehr JP (2008) Diversity and abundance of diazotrophs in the South China Sea during intermonsoon. ISME J 2:954-967

Moisander PH, Ochiai M, Lincoff A (2009) Nutrient limitation of Microcystis aeruginosa in Northern California Klamath River reservoirs. Harmful Algae, doi: 10.1016/j.hal.2009. 04.005

> Neilan BA, Jacobs D, Goodman AE (1995) Genetic diversity and phylogeny of toxic cyanobacteria determined by DNA polymorphisms within phycocyanin locus. Appl Environ Microbiol 61:3875-3883

Neilan BA, Jacobs D, Del Dot T, Blackall LL, Hawkins PR, Cox PT, Goodman AE (1997) rRNA sequences and evolutionary relationships among toxic and nontoxic cyanobacteria of the genus Microcystis. Int J Syst Bacteriol 47:693-697

Neilan BA, Dittmann E, Rouhiainen L, Bass RA, Schaub V, Sivonen K, Borner T (1999) Nonribosomal peptide synthesis and toxigenity of cyanobacteria. Appl Environ Microbiol 181:4089-4097

> Orr PT, Jones GJ, Douglas GB (2004) Response of cultured Microcystis aeruginosa from the Swan River, Australia, to elevated salt concentration and consequences for bloom and toxin management in estuaries. Mar Freshw Res 55: $277-283$

> Qiu B, Gao K (2002) Effects of $\mathrm{CO}_{2}$ enrichment on the bloomforming cyanobacterium Microcystis aeruginosa (Cyanophyceae): physiological responses and relationships with the availability of dissolved inorganic carbon. J Phycol 38:721-729

Rantala A, Fewer DP, Hisbergues M, Rouhiainen L, Vaitomaa J, Börner T, Sivonen K (2004) Phylogenetic evidence for the early evolution of microcystin synthesis. Proc Natl Acad Sci USA 101:568-573

Rinta-Kanto JM, Wilhelm SW (2006) Diversity of microcystinproducing cyanobacteria in spatially isolated regions in Lake Erie. Appl Environ Microbiol 72:5083-5085

Rippka R (1988) Isolation and purification of cyanobacteria. Methods Enzymol 167:3-27

Robson BJ, Hamilton DP (2003) Summer flow event induces a cyanobacterial bloom in a seasonal Western Australian estuary. Mar Freshw Res 54:139-151

Sellner K, Lacouture RV, Parris CR (1988) Effects of increasing salinity on a cyanobacteria bloom in the Potomac River estuary. J Plankton Res 10:49-61

Shapiro J (1989) Current beliefs regarding dominance by blue-greens: the case for the importance of $\mathrm{CO}_{2}$ and $\mathrm{pH}$. Int Ver Theor Angew Limnol Verh 24:38-54

Sivonen K, Jones G (1999) Cyanobacterial toxins. In: Chorus I, Bartram J (eds) Toxic cyanobacteria in water. E \& FN Spon, London, p 41-111

Sivonen K, Kononen K, Carmichael WW, Dahlem AM, Rinehart KL, Kiviranta J, Niemelä SI (1989) Occurrence of the hepatotoxic cyanobacterium Nodularia spumigena in the Baltic Sea and structure of the toxin. Appl Environ Microbiol 55:1990-1995 
Takamura N, Iwakama T, Yasuno M (1987) Uptake of ${ }^{13} \mathrm{C}$ and ${ }^{15} \mathrm{~N}$ (ammonium, nitrate and urea) by Microcystis in Lake Kasumigaura. J Plankton Res 9:151-165

Tamura K, Dudley J, Nei M, Kumar S (2007) MEGA 4: molecular evolutionary genetics analysis (MEGA) software version 4.0. Mol Biol Evol 24:1596-1599

Tillett D, Parker DL, Neilan BA (2001) Detection of toxigenity by a probe for the microcystin synthetase A gene (mcyA) of the cyanobacterial genus Microcystis: comparison of toxicities with 16S rRNA and phycocyanin operon (phycocyanin intergenic spacer) phylogenies. Appl Environ Microbiol 67:2810-2818

Tonk L, Bosch K, Visser PM, Huisman J (2007) Salt tolerance of the harmful cyanobacterium Microcystis aeruginosa. Aquat Microb Ecol 46:117-123

USEPA (US Environmental Protection Agency) (1983) Methods for chemical analysis of water and wastes. Technical Report EPA-600/4-79-020. USEPA, Washington, DC

Verspagen JMH, Passarge J, Jöhnk KD, Visser PM and others

Editorial responsibility: Jed Fuhrman,

Los Angeles, California, USA
(2006) Water management strategies against toxic MicroCystis blooms in the Dutch delta. Ecol Appl 16:313-327

WHO (World Health Organization) (2003) Guidelines for safe recreational waters. Vol 1: coastal and fresh waters. WHO, Geneva

Wilson AE, Sarnelle O, Neilan BA, Salmon TP, Gehringer MM, Hay ME (2005) Genetic variation of the bloom-forming cyanobacterium Microcystis aeruginosa within and among lakes: implications for harmful algal blooms. Appl Environ Microbiol 71:6126-6133

Ye WJ, Liu XL, Tan J, Li DT, Yang H (2009) Diversity and dynamics of microcystin-producing cyanobacteria in China's third largest lake, Lake Taihu. Harmful Algae 8: 637-644

Yoshida M, Yoshida T, Takashima Y, Hosoda N, Hiroishi S (2007) Dynamics of microcystin-producing and non-microcystin producing Microcystis populations is correlated with nitrate concentration in a Japanese lake. FEMS Microbiol Lett 266:49-53

Submitted: December 3, 2008; Accepted: May 5, 2009

Proofs received from author(s): August 20, 2009 